\title{
Synthesis of Photocrosslinkable Hyperbranched Polyesters with Terminal Methacryloyl Groups by the One-pot Polyaddition of Bis(oxetane)s with 1,3,5-Benzenetricarboxylic Acid and Methacrylic Acid
}

\author{
Tadatomi Nishikubo, ${ }^{1, \dagger}$ Hiroto Kudo, ${ }^{1}$ Ken Maruyama, ${ }^{1}$ \\ Takehiko NAKAGAMI, ${ }^{1}$ and Hidekazu MIYABE ${ }^{2}$ \\ ${ }^{1}$ Department of Applied Chemistry, Faculty of Engineering, Kanagawa University, \\ Rokkakubashi, Kanagawa-ku, Yokohama 221-8686, Japan \\ ${ }^{2}$ Technical Research Laboratory, Taiyo Ink Mfg. Co., Ltd., \\ 388 Ohkura, Ranzan-machi, Hiki-gun 355-0222, Japan
}

(Received October 24, 2005; Accepted January 9, 2006; Published May 15, 2006)

\begin{abstract}
The hyperbranched poly(ester)s with pendant primary hydroxy, methacryloyl, and oxetanyl groups were synthesized by the one-pot method for the polyaddition of bis(oxetane)s with 1,3,5-benzenetricarboxylic acid (TMA) and methacrylic acid (MA) in the presence of tetraphenylphosphonium chloride (TPPC) as a catalyst. A alkaline-developable photo-reactive hyperbranched polymer (P-4b) was prepared by the addition reaction of the synthesized hyperbranched poly(ester) P-4a with cis-1,2,3,6-tetrahydrophthalic anhydride (THPA). A resist composed of 58 wt $\%$ P-4b, 12 wt $\%$ dilute monomer, $5 \mathrm{wt} \%$ Irgacure $907^{\circledR}$ as a photo-initiator, $24 \mathrm{wt} \%$ epoxy resin, and $1 \mathrm{wt} \%$ dicyandiamide achieved a resolution of a $55 \mu \mathrm{m}$ line pattern and a $27 \mu \mathrm{m}$ space pattern by UV irradiation $(1000 \mathrm{~mJ})$ when $6 \mu \mathrm{m}$ thick film is used. [doi:10.1295/polymj.38.447]

KEY WORDS Oxetane / Hyperbranched Polymer / Polyaddition / Photo-radical Polymerization / Photo-resist / UV-curing System /
\end{abstract}

UV curing systems have been widely used in various applications ${ }^{1,2}$ such as coatings, printing inks, adhesives, photo-resists, and solder masks, because of their low volatile organic compound (VOC), high productivity, excellent physical properties, and energy saving. Recently, these systems have also been applied to electronics and information technology fields ${ }^{3}$ such as display, CD, DVD, optical-fiber, and opticaldevice. In these curing systems, acrylate monomers and oligomers are mainly used due to their high reactivity. Most of acrylate oligomers such as acrylated epoxy resins, poly(urethane)s, poly(ester)s, and poly(ether)s have relatively high viscosity, because these oligomers were composed from linear polymer chains in general.

More than 30 years ago, we $e^{4,5}$ reported the synthesis of polyesters with pendant hydroxy groups and (meth)acrylate groups by the addition reaction of epoxy resins with (meth)acrylic acid, which have been used as main resins in the fields of coatings and printing inks due to their high photochemical reactivity and excellent mechanical property. Furthermore, these oligomers were modified ${ }^{6}$ with cyclic carboxylic anhydride to form photo-curable oligomer with alkaline developable property. These (meth)acrylated epoxy resin derivatives have been widely used as main resin in solder masks in the world.
Meanwhile, hyperbranched polymers (HBPs) containing a large number of terminal groups possess a randomly branched structure ${ }^{7}$ and have recently attracted a great deal of attention for their unique properties such as lower viscosity, good solubility and many reactive terminal groups compared with the corresponding linear ones. Condensation polymers with hyperbranched structure are mainly synthesized ${ }^{8,9}$ by the one-step self-polycondensation of an $\mathrm{AB}_{m}$ type monomer which has one ' $A$ ' functional group and multiple ' $\mathrm{B}$ ' functional groups. However, these monomers are generally required to process tedious multistep organic synthesis and are unsuitable for industrial application on a large scale synthesis. To overcome this technical problem, Kakimoto and his co-workers ${ }^{10}$ substituted a new method by conventional combination of $A_{2}$ and $B_{3}$ monomers. Since the reaction system between $\mathrm{A}_{2}+\mathrm{B}_{3}$ monomers produced gel products in general, the control of the reaction condition is an important factor to obtain soluble hyperbranched polymer. However, this method is very convenient in practical applications, because commercially available numerous monomers can be used as starting materials. Recently, based on this concept, we reported ${ }^{11}$ the synthesis of photo-crosslinkable and alkaline developable hyperbranched poly(imide)s containing many terminal methacryloyl groups and

${ }^{\dagger}$ To whom correspondence should be addressed (E-mail: nishikubot@kanagawa-u.ac.jp). 

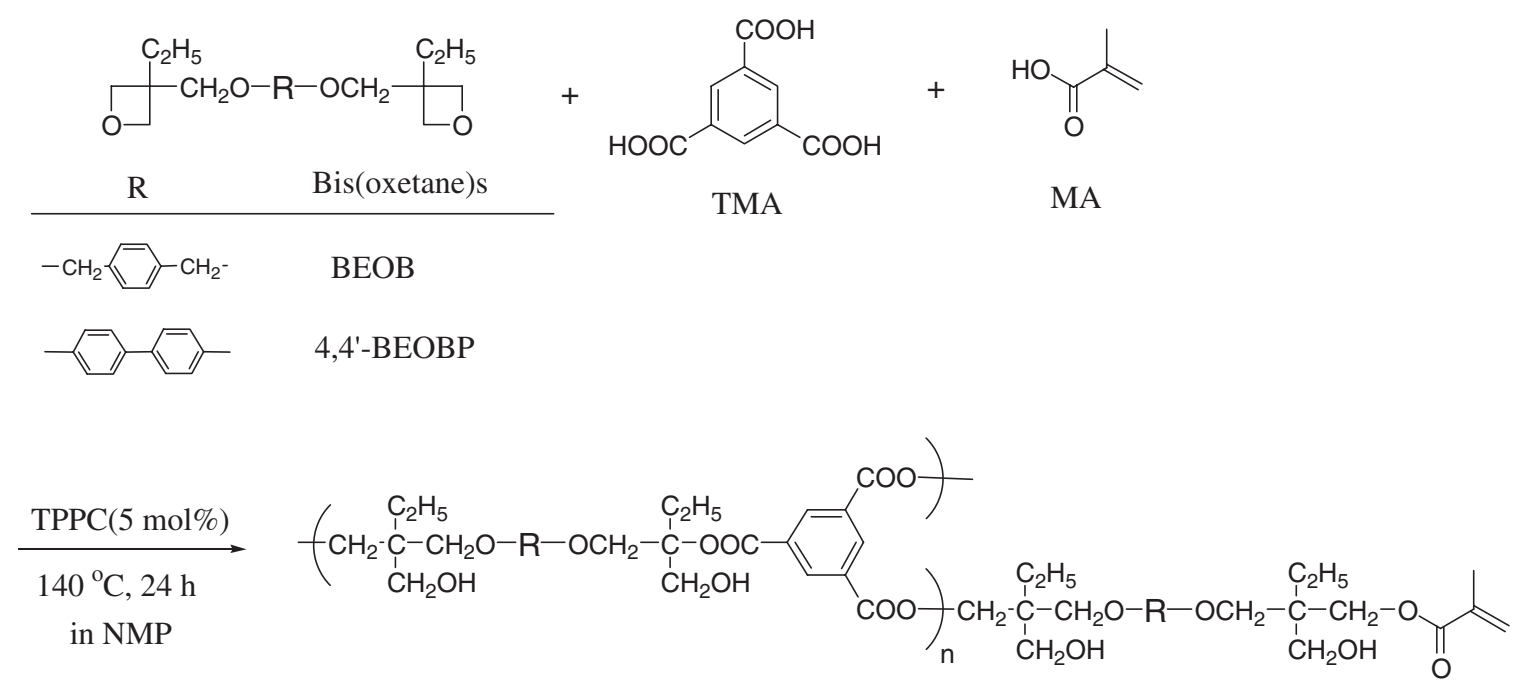

Hyperbranched polymer with terminal methacryloyl groups

Scheme 1.

pendant carboxyl groups by the reaction of tris-amine with tetracarboxylic dianhydrides followed by the reaction with glycidyl methacrylate and cis-1,2,3,6tetrahydrophthalic anhydride. Chen and Yin also reported $^{12}$ photo-crosslinkable hyperbranched poly(imide)s containing certain photoreactive groups. More recently, Thang et al., reported ${ }^{13}$ the synthesis of photo-curable hyperbranched poly(ester-amine)s with terminal acryloyl groups by the Michail addition reaction of piperazine $\left(A_{2}\right.$ monomer) with trimethylolpropane triacrylate $\left(\mathrm{B}_{3}\right.$ monomer).

On the other hand, we have recently found a new polyaddition reactions of bis(oxetane)s with dicarboxylic acids ${ }^{14}$ or bisphenols ${ }^{15-17}$ to produce the high molecular weight polyesters and polyethers with pendant primary hydroxy groups which can be use as the reactive groups for the introduction of functional groups, respectively. Given these background, we designed ${ }^{18}$ new hyperbranched poly(ester)s with pendant primary hydroxy groups as reactive groups by the polyaddition reaction of bis(oxetane)s with 1,3,5-benzenetricarboxylic acid (TMA). However, there are no reports on the synthesis of photo-curable and alkaline developable hyperbranched polymers excepting our recent two papers, ${ }^{11,19}$ although alkaline development property is a very important factor in practical application.

This article reports on the synthesis of the hyperbranched poly(ester)s by the polyaddition of bis(oxetane)s with TMA and methacrylic acid (MA) (Scheme 1). Furthermore, we examined the chemical modification of the synthesized hyperbranched poly(ester)s by the reaction of carboxylic anhydride to introduce alkaline developable property for the view point of practical application and its application for the UV curing resist system.

\section{EXPERIMENTAL}

\section{Materials}

Solvents were dried using $\mathrm{CaH}_{2}$ and purified in the usual way before use. Tetraphenylphosphonium chloride (TPPC), triphenylphosphine (TPP) were used without further purification. 3-Ethyl-3-phenoxymethyl oxetane (EPMO) (donated from Toagosei Co., Ltd.) was purified by distillation in vacuo. 1,4-Bis[(3ethyl-3-oxetanyl)methoxymethyl] benzene (BEOB), 4,4'-bis[(3-ethyl-3-oxetanyl)methoxy]biphenyl (4,4'BEOBP) (donated from Toagosei Co., Ltd.) and terephthalic acid (TPA) were purified by recrystallization from appropriate solvents. Reagent grade or commercial grade TMA, MA, cis-1,2,3,6-tetrahydrophthalic anhydride (THPA), Irgacure $907^{\circledR}$, 2-hydroxyethyl methacrylate (HEMA), dipentaerythrtol hexaacrylate (DPEHA), novolac-type epoxy-resin RE-306CA90 obtained from NIPPON KAYAKU CO. LTD., and other reagents were also used without further purification.

\section{Measurements}

Infrared (IR) absorption spectra were measured on a Jasco FT/IR-420 spectrometer. The ${ }^{1} \mathrm{H}$ NMR spectrum was recorded on JEOL JNM FX-200 instruments in $\mathrm{CDCl}_{3}$ or dimethyl sulfoxide- $d_{6}\left(\mathrm{DMSO}-d_{6}\right)$ with $\mathrm{Me}_{4} \mathrm{Si}$ (TMS) as an internal standard. HPLC analysis was carried out on a Japan Analytical Industry Model HPLC-909 liquid chromatography connected with a JAIGEL-1H-A column using tetrahydrofuran (THF) as an eluent. The purification and isolation of the reaction adducts of EPMO with TMA and MA were carried out using a recycling preparative HPLC (Japan Analytical Industry Co., Ltd.; model HPLC-908 liquid 
chromatography) connected with a JAIGEL-1H-AF and JAIGEL-1H-A columns using chloroform as an eluent. The number-average molecular weight $\left(M_{\mathrm{n}}\right)$ and weight-average molecular weight $\left(M_{\mathrm{w}}\right)$ of the polymer were estimated by size exclusion chromatography (SEC; TOSOH model HLC-8220) on TSK gel columns (SuperAW3000 $\times 1$ and SuperAW2500 $\times 3$ ) calibrated by narrow molecular weight distribution polystyrene standards and with a refractive index detector. $N, N$-dimethylformamide (DMF) containing $20 \mathrm{mmolL}^{-1}$ of lithium bromides and $20 \mathrm{mmolL}^{-1}$ of phosphoric acids was used as an eluent. Real-time Infrared (RT-IR) absorption spectra were recorded on a BIO-RAD Excalibur FTS-3000MX spectrometer equipped with a HOYA-SCHOTT EX250 UV light source. Glass transition temperatures $\left(T_{\mathrm{g}}\right) \mathrm{s}$ were measured on a Seiko Electronic Instruments model EXSTAR 6000/DSC6200 differential scanning calorimeter (DSC) at a heating rate of $10^{\circ} \mathrm{C} / \mathrm{min}$ under nitrogen atmosphere. Thermal analysis (TGA) was performed on a Seiko Electronic Instruments model EXSTAR 6000/TG/DTA 6220 at a heating rate of $10^{\circ} \mathrm{C} / \mathrm{min}$ under nitrogen.

\section{Model Reaction of EPMO with TMA and MA}

The measurement of the reaction rate was as follows: The mixture of EPMO (2.304 g; $12 \mathrm{mmol})$, TMA $(0.420 \mathrm{~g} ; 2 \mathrm{mmol})$, MA $(0.517 \mathrm{~g} ; 6 \mathrm{mmol})$, TPPC $(0.225 \mathrm{~g} ; 5 \mathrm{~mol} \%$ to EPMO as the catalyst), and hydroquinone (HQ) $(0.013 \mathrm{~g})$ as an inhibitor in 1-methyl2-pyrrolidinone (NMP) $(5 \mathrm{~mL})$ stirred at $140^{\circ} \mathrm{C}$ under nitrogen. The degrees of addition reactions of EPMO with TMA and MA at each time were measured by HPLC (Figure 1).

The identification of the reaction products was as follows: EPMO (2.304 g; $12 \mathrm{mmol})$, TMA $(0.420 \mathrm{~g}$; $2 \mathrm{mmol}), \mathrm{MA}(0.517 \mathrm{~g} ; 6 \mathrm{mmol})$, and TPPC $(0.225 \mathrm{~g}$; $5 \mathrm{~mol} \%$ to EPMO) were dissolved in NMP $(5 \mathrm{~mL})$, and stirred at $140{ }^{\circ} \mathrm{C}$ for $6 \mathrm{~h}$ in the presence of HQ $(0.013 \mathrm{~g})$ as an inhibitor under nitrogen. The reaction mixture was diluted with chloroform, and then washed

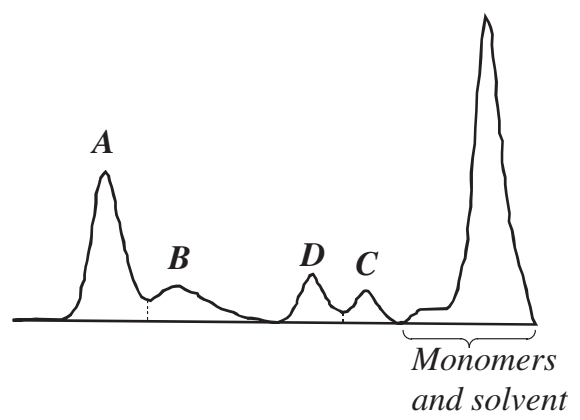

Figure 1. HPLC chromatogram for the reaction of EPMO with TMA and MA using TPPC as a catalyst at $140^{\circ} \mathrm{C}$ for $6 \mathrm{~h}$ in NMP. trice with water. The obtained organic layer was dried with $\mathrm{MgSO}_{4}$, and then resulting organic phase was evaporated. The obtained crude residues were separated using a recycling preparative HPLC to give three products $(\mathrm{A}, \mathrm{B}$, and $\mathrm{C})$, which structures were confirmed by IR and ${ }^{1} \mathrm{H}$ NMR spectroscopy.

Adduct A from TMA with three EPMO: IR (bulk, $\left.\mathrm{cm}^{-1}\right): 3440(v \mathrm{OH}), 1731(v \mathrm{C}=\mathrm{O}$, ester), 1599 and 1497 ( $v \mathrm{C}=\mathrm{C}$ of aromatic), and 1239 ( $v \mathrm{C}-\mathrm{O}-\mathrm{C}$, ester). ${ }^{1} \mathrm{H} \mathrm{NMR}\left(200 \mathrm{MHz}, \mathrm{CDCl}_{3}, \mathrm{TMS}\right) \delta=0.96$ $\left(\mathrm{t}, J=7.5 \mathrm{~Hz}, 9.0 \mathrm{H}, \mathrm{CH}_{2} \mathrm{CH}_{3}\right), 1.63(\mathrm{q}, J=7.5 \mathrm{~Hz}$, $6.0 \mathrm{H}, \mathrm{CH}_{2} \mathrm{CH}_{3}$ ), 2.20-2.40 (brs, $3.0 \mathrm{H}, \mathrm{OH}$ ), 3.73 (s, $\left.6.0 \mathrm{H}, \mathrm{C}-\mathrm{CH}_{2}-\mathrm{OH}\right), 3.97\left(\mathrm{~s}, 6.0 \mathrm{H}, \mathrm{O}-\mathrm{CH}_{2}-\mathrm{C}\right), 4.49$ (s, $\left.6.0 \mathrm{H}, \mathrm{CO}_{2}-\mathrm{CH}_{2}-\mathrm{C}\right)$, and $6.85-7.40(\mathrm{~m}, 15.0 \mathrm{H}$, aromatic $\mathrm{H}$ in EPMO unit), 8.70-8.80 ppm (m, 3.0H, aromatic $\mathrm{H}$ in TMA unit).

Adduct B from TMA with two EPMO: IR (bulk, $\left.\mathrm{cm}^{-1}\right): 3600-3500(v \mathrm{OH}$ and $\mathrm{COOH}), 1729(v \mathrm{C}=\mathrm{O}$, ester and carboxyl group), 1599 and 1497 ( $\nu \mathrm{C}=\mathrm{C}$ of aromatic), and 1239 ( $v \mathrm{C}-\mathrm{O}-\mathrm{C}$, ester). ${ }^{1} \mathrm{H}$ NMR (200 $\left.\mathrm{MHz}, \mathrm{CDCl}_{3}, \mathrm{TMS}\right) \delta=0.98(\mathrm{t}, J=7.5 \mathrm{~Hz}, 6.0 \mathrm{H}$, $\mathrm{CH}_{2} \mathrm{CH}_{3}$ ), 1.65 (q, $\left.J=7.5 \mathrm{~Hz}, 4.0 \mathrm{H}, \mathrm{CH}_{2} \mathrm{CH}_{3}\right), 3.81$ (s, $\left.4.0 \mathrm{H}, \mathrm{C}-\mathrm{C}_{2}-\mathrm{OH}\right), 3.99$ (s, $4.0 \mathrm{H}, \mathrm{O}-\mathrm{CH}_{2}-\mathrm{C}$ ), 4.49 (s, 4.0H, $\mathrm{CO}_{2}-\mathrm{CH}_{2}-\mathrm{C}$ ), 5.00-5.60 (brs, $1.9 \mathrm{H}, \mathrm{OH}$ ), $6.70-7.40(\mathrm{~m}, 10.0 \mathrm{H}$, aromatic $\mathrm{H}$ in EPMO unit), and $8.60-8.90 \mathrm{ppm}$ ( $\mathrm{m}, 3.0 \mathrm{H}$, aromatic $\mathrm{H}$ in TMA unit).

Adduct $\mathrm{C}$ from MA with EPMO: IR (bulk, $\mathrm{cm}^{-1}$ ): 3448 ( $v \mathrm{OH}), 1732$ ( $v \mathrm{C}=\mathrm{O}$, ester), $1637(v \mathrm{C}=\mathrm{C}$, vinyl), 1599 and 1497 ( $v \mathrm{C}=\mathrm{C}$ of aromatic), $1245(v$ $\mathrm{C}-\mathrm{O}-\mathrm{C}$, ester), and 810 ( $v \mathrm{C}-\mathrm{H}$, vinyl). ${ }^{1} \mathrm{H}$ NMR $\left(200 \mathrm{MHz}, \mathrm{CDCl}_{3}, \mathrm{TMS}\right) \delta=0.94(\mathrm{t}, J=7.5 \mathrm{~Hz}$, $\left.3.0 \mathrm{H}, \mathrm{CH}_{2} \mathrm{CH}_{3}\right), 1.58$ (q, $J=7.5 \mathrm{~Hz}, 2.0 \mathrm{H}, \mathrm{C}_{2} \mathrm{CH}_{3}$ ), 1.94 (s, 3.0H, $\mathrm{CH}_{3}$ ), 2.20-2.60 (brs, $1.0 \mathrm{H}, \mathrm{OH}$ ), 3.64 (s, 2.0H, C- $\left.\mathrm{CH}_{2}-\mathrm{OH}\right), 3.92$ (s, $2.0 \mathrm{H}, \mathrm{O}-\mathrm{CH}_{2}-\mathrm{C}$ ), 4.27 (s, $\left.2.0 \mathrm{H}, \mathrm{CO}_{2}-\mathrm{C}_{2}-\mathrm{C}\right), 5.58$ and $6.11(\mathrm{~s}, 2.0 \mathrm{H}, \mathrm{C}=$ $\left.\mathrm{CH}_{2}\right)$, and $6.80-7.40 \mathrm{ppm}(\mathrm{m}, 5.0 \mathrm{H}$, aromatic $\mathrm{H}$ in EPMO unit).

\section{Polyaddition of BEOB with TMA and MA}

A typical procedure for the polyaddition of $\mathrm{BEOB}$ with TMA and MA was as follows: BEOB (1.002 g; $3 \mathrm{mmol})$, TMA $(0.210 \mathrm{~g} ; 1 \mathrm{mmol})$, MA $(0.254 \mathrm{~g}$; $3 \mathrm{mmol})$, TPPC $(0.056 \mathrm{~g} ; 0.15 \mathrm{mmol})$, HQ $(0.017 \mathrm{~g}$; $0.15 \mathrm{mmol})$, and NMP $(2 \mathrm{~mL})$ were charged into a round-bottomed flask under a stream of dried air. The reaction was performed at $140^{\circ} \mathrm{C}$ for $24 \mathrm{~h}$ under stirring, and then the solution was poured into a large amount of water to precipitate the polymer. The resulting polymer was reprecipitated from THF into $n$-hexane, reprecipitated from THF into diethyl ether, and then dried in vacuo to yield a brown-colored solid. The yield of polymer (P-2a) was $0.86 \mathrm{~g}(58 \%)$. $M_{\mathrm{n}}$ of the polymer estimated by SEC was $4200\left(M_{\mathrm{w}} /\right.$ $\left.M_{\mathrm{n}}=3.02\right)$. The ratio of methacryloyl groups in the end of polymer chain (RM) was $16 \%$, which was cal- 
culated by the intensity ratio of ${ }^{1} \mathrm{H}$ NMR. The content of $\mathrm{COOH}$ groups in the polymer chain was $4.57 \%$, which was measured by neutralization titration of the carboxyl groups using 0.01-N ethanolic aqueous solution in THF. IR (film, $\left.\mathrm{cm}^{-1}\right)$ : $3388(v \mathrm{O}-\mathrm{H}), 1729(v$ $\mathrm{C}=\mathrm{O}$, ester $), 1636(v \mathrm{C}=\mathrm{C}$, vinyl $), 1461 \quad(v \mathrm{C}=\mathrm{C}$, aromatic), 1241 ( $v$ C-O-C, ester), 1096 and 1051 ( $v$ $\mathrm{C}-\mathrm{O}-\mathrm{C}$, ether), and 992 ( $v \mathrm{C}-\mathrm{O}-\mathrm{C}$, cyclic ether of oxetane), and 817 (v C-H, vinyl). ${ }^{1} \mathrm{H}$ NMR $(200 \mathrm{MHz}$, DMSO- $d_{6}$, TMS): $0.75-1.05\left(\mathrm{~m}, 12.4 \mathrm{H}, \mathrm{CH}_{2}-\mathrm{CH}_{3}\right)$, $1.20-1.70\left(\mathrm{~m}, 8.2 \mathrm{H}, \mathrm{CH}_{2}-\mathrm{CH}_{3}\right), 1.70-1.85(\mathrm{~s}, 1.0 \mathrm{H}$, $\left.\mathrm{C}\left(\mathrm{CH}_{3}\right)=\mathrm{CH}_{2}\right), 3.00-3.75\left(\mathrm{~m}, 16.8 \mathrm{H}, \mathrm{C}-\mathrm{CH}_{2}-\mathrm{O}, \mathrm{C}-\right.$ $\mathrm{CH}_{2}-\mathrm{OH}$, and $\left.\mathrm{OH}\right), 4.10-4.80$ (m, $19.3 \mathrm{H}, \mathrm{COO}-\mathrm{C}_{2}-$ $\mathrm{C}, \mathrm{O}-\mathrm{CH}_{2}-\mathrm{Ar}$, and $\mathrm{CH}_{2}-\mathrm{O}$ in oxetane ring), 5.57 and $5.94\left(\mathrm{~s}, 0.7 \mathrm{H}, \mathrm{C}\left(\mathrm{CH}_{3}\right)=\mathrm{CH}_{2}\right), 6.95-7.40(\mathrm{~m}, 8.3 \mathrm{H}$, aromatic $\mathrm{H}$ in $\mathrm{BEOB}$ unit), and $8.40-8.80 \mathrm{ppm}(\mathrm{m}$, $3.0 \mathrm{H}$, aromatic $\mathrm{H}$ in TMA unit).

\section{Polyaddition of 4,4'-BEOBP with TMA and MA}

The polyaddition of 4,4'-BEOBP $(1.15 \mathrm{~g} ; 3 \mathrm{mmol})$, TMA $(0.210 \mathrm{~g} ; 1 \mathrm{mmol})$ and MA $(0.775 \mathrm{~g} ; 9 \mathrm{mmol})$ was performed in NMP $(2 \mathrm{~mL})$ using TPPC $(0.056 \mathrm{~g}$; $0.15 \mathrm{mmol})$ as a catalyst and HQ $(0.017 \mathrm{~g})$ as an radical polymerization inhibitor at $140^{\circ} \mathrm{C}$ for $24 \mathrm{~h}$. The resulting mixture was poured into a large amount of water to precipitate the polymer. The resulting polymer was reprecipitated from THF into $n$-hexane, reprecipitated from THF into diethyl ether, and then dried in vacuo to yield a brown-colored solid. The yield of polymer (P-6a) was $1.25 \mathrm{~g}(53 \%)$. RM was $57 \%$, which was calculated by the intensity ratio of ${ }^{1} \mathrm{H}$ NMR. $M_{\mathrm{n}}=3800, M_{\mathrm{w}} / M_{\mathrm{n}}=2.20$. IR (film, $\left.\mathrm{cm}^{-1}\right): 3430$ ( $\left.v \mathrm{O}-\mathrm{H}\right), 1725$ ( $v \mathrm{C}=\mathrm{O}$, ester), 1636 ( $v$ $\mathrm{C}=\mathrm{C}$, vinyl), 1500 ( $v \mathrm{C}=\mathrm{C}$, aromatic), 1237 ( $v \mathrm{C}-\mathrm{O}-$ $\mathrm{C}$ ester), 997 ( $v \mathrm{C}-\mathrm{O}-\mathrm{C}$, cyclic ether of oxetane), and 821 (v C-H, vinyl). ${ }^{1} \mathrm{H}$ NMR $\left(200 \mathrm{MHz}, \mathrm{DMSO}-d_{6}\right.$, TMS) $\delta=0.82-1.05\left(\mathrm{~m}, 6.0 \mathrm{H}, \mathrm{CH}_{2}-\mathrm{CH}_{3}\right), 1.30-1.75$ $\left(\mathrm{m}, 4.0 \mathrm{H}, \mathrm{C}_{2}-\mathrm{CH}_{3}\right), 1.75-1.85\left(\mathrm{~s}, 1.5 \mathrm{H}, \mathrm{C}\left(\mathrm{CH}_{3}\right)=\right.$ $\mathrm{CH}_{2}$ ), 3.10-4.80 (m, $14.0 \mathrm{H}, \mathrm{C}-\mathrm{CH}_{2}-\mathrm{O}-$ biphenyl unit, $\mathrm{C}-\mathrm{CH}_{2}-\mathrm{OH}, \mathrm{COO}-\mathrm{C}_{2}-\mathrm{C}, \mathrm{CH}_{2}-\mathrm{O}$ in oxetane ring, and $\mathrm{OH}), 5.58$ and $6.02\left(\mathrm{~s}, 1.0 \mathrm{H}, \mathrm{C}\left(\mathrm{CH}_{3}\right)=\mathrm{CH}_{2}\right)$, 6.55-7.64 $(\mathrm{m}, 8.0 \mathrm{H}$, aromatic $\mathrm{H}$ in bisphenol), and $8.55-8.72 \mathrm{ppm}(\mathrm{m}, 1.5 \mathrm{H}$, aromatic $\mathrm{H}$ in TMA unit).

\section{Polyaddition of BEOB with TPA and MA}

The mixture of BEOB $(2.01 \mathrm{~g}, 6 \mathrm{mmol})$, TPA (0.83 $\mathrm{g}, 5 \mathrm{mmol})$, TPPC $(0.23 \mathrm{~g}, 0.6 \mathrm{mmol})$ in NMP $(2 \mathrm{~mL})$ was stirred at $140^{\circ} \mathrm{C}$ for $30 \mathrm{~h}$. Then, MA $(2.58 \mathrm{~g}$, $30 \mathrm{mmol}$ ) and HQ (0.17) were added to the reaction mixture and stirred for additional $18 \mathrm{~h}$. The resulting mixture was poured into a large amount of water to precipitate the polymer. The resulting polymer was reprecipitated twice from THF into diethyl ether, and then dried in vacuo to yield a brown-colored solid. The yield of polymer (P-7a) was $2.37 \mathrm{~g}(88 \%)$. RM was $95 \%$, which was calculated by the intensity ratio of ${ }^{1} \mathrm{H}$ NMR. $M_{\mathrm{n}}=3800, M_{\mathrm{w}} / M_{\mathrm{n}}=2.30$. IR (film, $\left.\mathrm{cm}^{-1}\right): 3388$ ( $\left.v \mathrm{O}-\mathrm{H}\right), 1730$ ( $v \mathrm{C}=\mathrm{O}$, ester), 1636 ( $v$ $\mathrm{C}=\mathrm{C}$, vinyl), 1463 ( $v \mathrm{C}=\mathrm{C}$, aromatic), 1243 ( $v \mathrm{C}-$ O-C, ester), 1100 and 1055 ( $v$ C-O-C, ether), and 816 ( $v$ C-H, vinyl). ${ }^{1} \mathrm{H}$ NMR $\left(200 \mathrm{MHz}, \mathrm{DMSO}-d_{6}, \mathrm{TMS}\right)$ : 0.65-0.95 (m, 6.0H, $\left.\mathrm{CH}_{2}-\mathrm{CH}_{3}\right), 1.11-1.68(\mathrm{~m}, 4.0 \mathrm{H}$, $\left.\mathrm{C}_{2}-\mathrm{CH}_{3}\right), 1.71-1.85\left(\mathrm{~s}, 0.9 \mathrm{H}, \mathrm{C}\left(\mathrm{CH}_{3}\right)=\mathrm{CH}_{2}\right), 3.10$ $3.72\left(\mathrm{~m}, 7.9 \mathrm{H}, \mathrm{C}-\mathrm{CH}_{2}-\mathrm{O}\right.$ and $\left.\mathrm{C}-\mathrm{CH}_{2}-\mathrm{OH}\right), 3.80-$ $4.81\left(\mathrm{~m}, 9.5 \mathrm{H}, \mathrm{COO}-\mathrm{CH}_{2}-\mathrm{C}, \mathrm{O}-\mathrm{C}_{2}-\mathrm{Ar}\right.$, and $\left.\mathrm{OH}\right)$, 5.41 and $6.00\left(\mathrm{~s}, 0.6 \mathrm{H}, \mathrm{C}\left(\mathrm{CH}_{3}\right)=\mathrm{CH}_{2}\right), 6.94-7.33$ $(\mathrm{m}, 4.0 \mathrm{H}$, aromatic $\mathrm{H}$ in $\mathrm{BEOB}$ unit), and 7.82-8.20 ppm $(\mathrm{m}, 3.7 \mathrm{H}$, aromatic $\mathrm{H}$ in TPA unit).

\section{Chemical Modification of the Hyperbranched Polymer $4 a(P-4 a)$}

The reaction of P-4a $(0.199 \mathrm{~g} ; 1.0 \mathrm{mmol}$ as hydroxyl group, $M_{\mathrm{n}}=3600, M_{\mathrm{w}} / M_{\mathrm{n}}=2.01, \mathrm{RM}=54 \%$ ), with THPA $(0.091 \mathrm{~g} ; 0.6 \mathrm{mmol})$ was carried out in the presence of TPP $(0.05 \mathrm{~g} ; 0.20 \mathrm{mmol})$ as a catalyst in 1,4-dioxane $(0.3 \mathrm{~mL})$ at $80^{\circ} \mathrm{C}$ for $4 \mathrm{~h}$. Then, the reaction mixture was diluted with THF, washed thrice with large amount of water to remove TPP and poured into $n$-hexane to precipitate the polymer, and dried in vacuo. The yield of polymer (P-4b) was $0.23 \mathrm{~g} \mathrm{(79 \% ).}$ The degree of conversion of hydroxyl groups was $55 \%$, which was calculated by the intensity ratio of ${ }^{1} \mathrm{H}$ NMR. The content of $\mathrm{COOH}$ groups in the polymer chain was $11.4 \%$, which was measured by neutralization titration of the pendant carboxyl groups using 0.01-N ethanolic aqueous solution in THF. IR (film, $\left.\mathrm{cm}^{-1}\right)$ : 2500-3500 (O-H, $\left.\mathrm{COOH}\right), 1733(\mathrm{C}=\mathrm{O}$, ester, carboxylate), $1462(\mathrm{C}=\mathrm{C}$, aromatic $), 1238(\mathrm{C}-$ $\mathrm{O}-\mathrm{C}$, ester), and 992 (C-O-C, cyclic ether of oxetane). ${ }^{1} \mathrm{H}$ NMR (200 MHz, DMSO- $d_{6}$, TMS): 0.75$1.05\left(\mathrm{~m}, 6.1 \mathrm{H}, \mathrm{CH}_{2}-\mathrm{CH}_{3}\right), 1.20-1.70\left(\mathrm{~m}, 4.0 \mathrm{H}, \mathrm{CH}_{2}-\right.$ $\left.\mathrm{CH}_{3}\right), 1.70-1.85\left(\mathrm{~m}, 1.4 \mathrm{H}, \mathrm{C}\left(\mathrm{CH}_{3}\right)=\mathrm{CH}_{2}\right), 2.20-2.65$ $\left(\mathrm{m}, 3.0 \mathrm{H}, \mathrm{CH}-\mathrm{CH}_{2}-\mathrm{CH}=\right.$ in THPA unit), $2.80-3.75$ (m, $9.5 \mathrm{H}$, OCO-CH$-\mathrm{CH}_{2}$ in THPA unit, $\mathrm{C}-\mathrm{CH}_{2}-\mathrm{O}$, $\mathrm{C}-\mathrm{CH}_{2}-\mathrm{OH}$, and $\left.\mathrm{OH}\right), 4.10-4.80(\mathrm{~m}, 10.2 \mathrm{H}, \mathrm{COO}-$ $\mathrm{CH}_{2}-\mathrm{C}, \mathrm{O}-\mathrm{CH}_{2}-\mathrm{Ar}$, and $\mathrm{CH}_{2}-\mathrm{O}$ in oxetane ring), 5.40-5.70 (m, 2.0H, $\mathrm{CH}_{2}-\mathrm{CH}=$ in THPA unit and $\left.\mathrm{C}\left(\mathrm{CH}_{3}\right)=\mathrm{CH}_{2}\right), 5.94\left(\mathrm{~s}, 0.5 \mathrm{H}, \mathrm{C}\left(\mathrm{CH}_{3}\right)=\mathrm{CH}_{2}\right), 6.95-$ $7.40(\mathrm{~m}, 4.0 \mathrm{H}$, aromatic $\mathrm{H}$ in BEOB unit), and 8.40$8.80 \mathrm{ppm}(\mathrm{m}, 1.5 \mathrm{H}$, aromatic $\mathrm{H}$ in TMA unit).

\section{Photo-initiated Radical Polymerization}

A typical procedure for the photo-initiated radical polymerization was as follows: The photo-initiated radical polymerization of P-4a $\left(M_{\mathrm{n}}=3600, M_{\mathrm{w}} /\right.$ $\left.M_{\mathrm{n}}=2.01, \mathrm{RM}=54 \%\right)$ was performed in the film state as follows. P-4a $(97 \mathrm{wt} \%)$ and Irgacure $907^{\circledR}$ $(3 \mathrm{wt} \%)$ as a photo-initiator were dissolved in THF and dried to make film on the plate. The film, containing a photo-initiator on the plate, was irradiated 


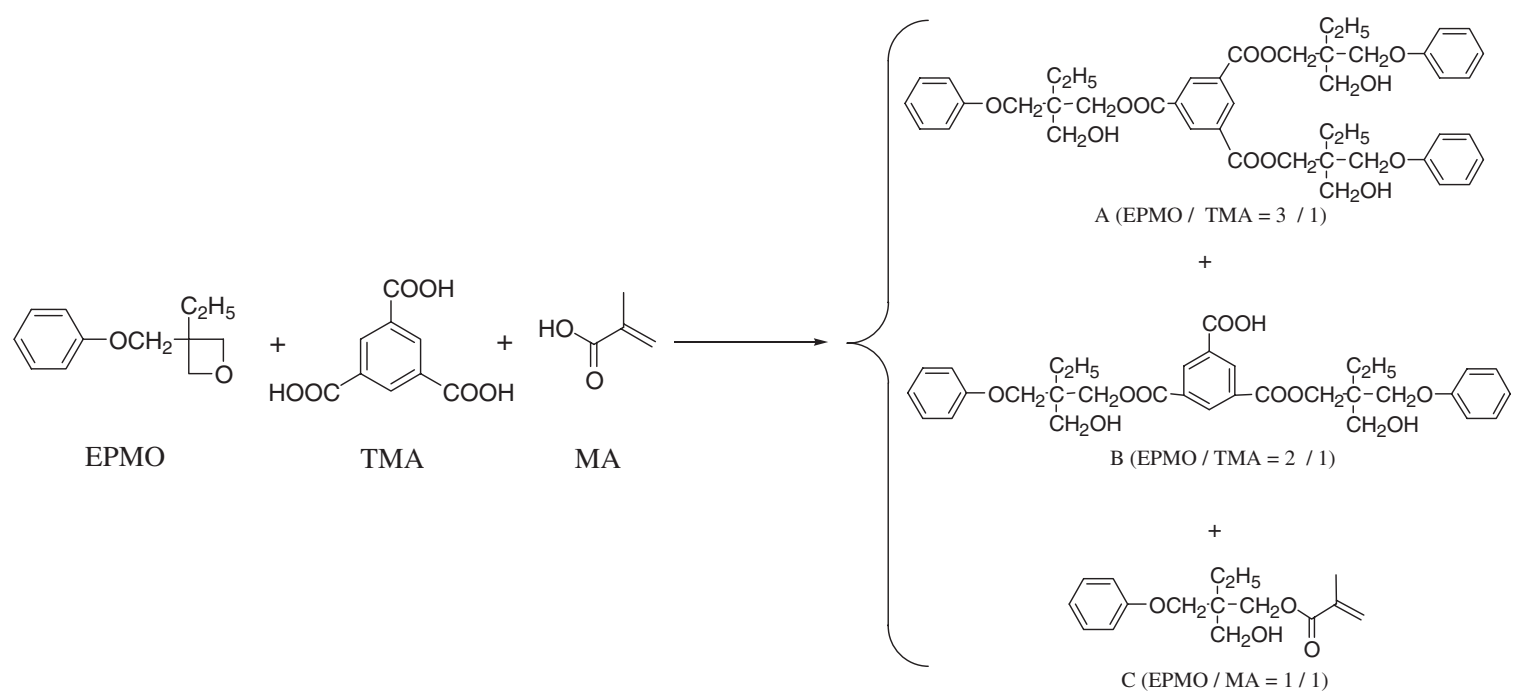

Scheme 2.

with a 250-W high-pressure mercury lamp (HOYASCHOTT Co.) without a filter under air. The intensity of the light was kept at $8 \mathrm{~mW} / \mathrm{cm}^{2}$ (at $254 \mathrm{~nm}$ ). The rate of decrease in the $\mathrm{C}=\mathrm{C}$ stretching near 1636 $\mathrm{cm}^{-1}$ due to methacryloyl group in P-4a was measured by RT-IR.

\section{Preparation and Evaluation of Solder Resist}

Tyipical procedure for the preparation of solder resist was as follows. The solution of solder resist (Sample 1) was prepared from $58 \mathrm{wt} \%$ of $\mathbf{P}-\mathbf{4} \mathbf{b}$ as a main resin, $12 \mathrm{wt} \%$ of DPEHA as a diluent, $5 \mathrm{wt} \%$ of Irgacure $907^{\circledR}$ as a photo-initiator, $24 \mathrm{wt} \%$ of novolac type epoxy resin as a thermal curing agent, $1 \mathrm{wt} \%$ of dicyandiamide as an additive, and diethylene glycol monoethyl ether acetate as a solvent $(40 \mathrm{wt} \%$ to $\mathbf{P}-\mathbf{4 b}$ ), and this solution was coated onto a substrate with a bar coater with a wet film. The coated substrate was heated at $80^{\circ} \mathrm{C}$ for $20 \mathrm{~min}$ to remove the solvent and exposed by broad-band UV light $\left(500 \mathrm{~mJ} / \mathrm{cm}^{2}\right)$. After that, the exposed resist film on the substrates was developed by putting spray with $1 \mathrm{wt} \%$ of $\mathrm{Na}_{2} \mathrm{CO}_{3}$ aqueous solution for $60 \mathrm{~min}$, being rinsed with water, and dried. The obtained negative pattern was measured with a scanning electron micrograph (SEM) image.

\section{RESULTS AND DISCUSSION}

\section{Model Reaction}

As a model reaction for the polyaddition of bis(oxetane)s with TMA and MA, the reaction of EPMO $(12 \mathrm{mmol})$ with TMA $(2 \mathrm{mmol})$ and MA $(6 \mathrm{mmol})$ was examined in NMP using $5 \mathrm{~mol} \%$ of TPPC as a catalyst at $140^{\circ} \mathrm{C}$ (Scheme 2). As shown in Figure 1, new appearances of certain peaks were conformed in HPLC chloromatogram, when the reaction was carried out for $6 \mathrm{~h}$. Therefore, these three fractions corresponding to three peaks $\mathrm{A}, \mathrm{B}$, and $\mathrm{C}$ were separated by recycling HPLC, and their structures were confirmed by ${ }^{1} \mathrm{H}$ NMR and IR spectroscopy. As the result, the fraction A was a compound obtained by the addition reaction of one-equivalent of TMA with three-equivalent of EPMO. The fraction B consisted of the compound obtained by the addition reaction of one-equivalent of TMA with two-equivalent of $\mathrm{EPMO}$, and fraction $\mathrm{C}$ was done of that by the equivalent addition reaction of MA with EPMO, respectively. These reactions and structures are illustrated in Scheme 2. Furthermore, although we could not isolate a product obtained by the equivalent addition reaction of TMA with EPMO, peak D seems to be a corresponding adduct. This means that the addition reaction of EPMO with TMA and MA proceeded to give the targeted products.

Based on the above result, conversion rates of TMA and MA on the reaction with EPMO were measured by HPLC. As shown in Figure 2, conversions of TMA and MA gradually increased and reached 40 and $9 \%$ at $12 \mathrm{~h}$, respectively. This result means that the reaction rate of TMA to EPMO was higher than that of MA to EPMO under competition conditions. Therefore, the one pot polyaddition of bis(oxetane) and TMA in the presence of MA can proceed under appropriate conditions to afford the corresponding hyperbranched polyesters with pendant primary hydroxy groups in the side chain and terminal methacryloyl groups at the ends.

Synthesis of Novel Hyperbranched Poly(ester)s with Terminal Methacryloyl Groups

The polyaddition of equimolar BEOB with TMA $(3 / 2$ as feed ratio) was carried out in the presence of TPPC as a catalyst $(5 \mathrm{~mol} \%)$ at $140^{\circ} \mathrm{C}$ for $24 \mathrm{~h}$ 


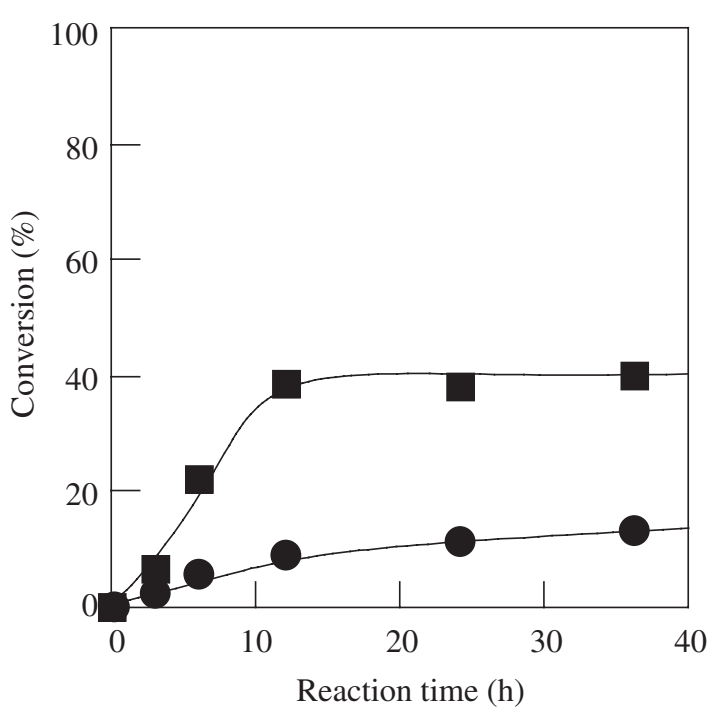

Figure 2. Conversion rate of TMA and MA on the reaction with EPMO. (๘): TMA, (•): MA.

to obtain the corresponding polymer in $96 \%$ yield. However, all of the reaction products were insoluble in common organic solvents, which means that the gelatin occurred during the polyaddition of BEOB with TMA under the above conditions.

On the other hand, when the polyaddition of BEOB and TMA was performed with the feed ratio of $3 / 1$ in feed at $140^{\circ} \mathrm{C}$ for $24 \mathrm{~h}$, soluble polymer P-1a with $M_{\mathrm{n}}=4000\left(M_{\mathrm{w}} / M_{\mathrm{n}}=2.90\right)$ was obtained in $68 \%$ yield (run 1 in Table I). The structure of P-1a was confirmed by IR and ${ }^{1} \mathrm{H}$ NMR spectroscopys. It was found that P-1a was hyperbranched polymer with pendant primary hydroxy groups in the side chain. Detail reaction conditions and results have been reported $^{18}$ in the previous paper. This means that the controlled reaction time and feed ratios of these polyaddition can offer the soluble hyperbranched polymer on the reaction of bis(oxetane) with TMA.

Based on the results of model reaction and the above reaction of BEOB with TMA, we examined the polyaddition of BEOB and TMA in the presence of MA under the similar conditions (Scheme 1). In feed ratio of $\mathrm{BEOB} / \mathrm{TMA} / \mathrm{MA}=3 / 1 / 3$, the hyperbranched poly(ester), P-2a containing $16 \%$ of terminal methacryloyl groups was obtained in $58 \%$ yield (run 2 in Table I). The structure of P-2a was confirmed by IR and ${ }^{1} \mathrm{H}$ NMR spectroscopy. It was also observed that the ratio of methacryloyl groups in the obtained hyperbranched poly(ester)s increased with increase of the concentration of MA in feed (runs 3-5 in Table I). P-6a which had rigid structure, with pendant primary hydroxy groups and terminal methacryloyl groups was also synthesized by the polyaddition of 4,4'-BEOBP with TMA and MA (feed ratio of $\mathrm{BEOBP} / \mathrm{TMA} / \mathrm{MA}=3 / 1 / 9)$ under the same reaction conditions. Furthermore, as shown in Figure 2, the rate of addition reaction of oxetane groups with TMA was much higher than that of oxetane groups with MA.

From all these results, it was concluded that the hyperbranched poly(ester)s with pendant primary hydroxy groups and certain terminal methacryloyl groups were synthesized by the one-pot method of the polyaddition of bis(oxetane)s with TMA and MA, although terminal oxetane groups were remained in the obtained polymers.

Furthermore, to compare the photochemical reactivity between the hyperbranched polymer and linear polymer, we synthesized the linear polyester P-7a with $M_{\mathrm{n}}=3800, M_{\mathrm{w}} / M_{\mathrm{n}}=2.30$ by the polyaddition of BEOB with TPA and MA under the same reaction conditions as mentioned above.

Photo-initiated Radical Polymerization of the Hyperbranched Polyester with Terminal Methacryloyl Groups

The photo-initiated radical polymerization of $\mathbf{P}-\mathbf{4 a}$ $\left(M_{\mathrm{n}}=3600, M_{\mathrm{w}} / M_{\mathrm{n}}=2.01, \mathrm{RM}=54 \%\right)$ was per-

Table I. Synthesis of hyperbranched poly(ester)s containing methacryloyl groups

\begin{tabular}{|c|c|c|c|c|c|c|c|c|}
\hline \multirow{2}{*}{ Run } & \multirow{2}{*}{ Polymer } & \multicolumn{3}{|c|}{ Feed ratio $(\mathrm{mmol})$} & \multirow{2}{*}{ Yield $(\%)^{\mathrm{c}}$} & \multirow{2}{*}{$M_{\mathrm{n}} \times 10^{-3 \mathrm{~d}}$} & \multirow{2}{*}{$M_{\mathrm{w}} / M_{\mathrm{n}}^{\mathrm{d}}$} & \multirow{2}{*}{$\mathrm{RM}(\%)^{\mathrm{e}}$} \\
\hline & & Bis(oxetane)s & TMA & MA & & & & \\
\hline $1^{\mathrm{a}}$ & P-1a & BEOB 3 & 1 & 0 & 68 & 4.0 & 2.90 & - \\
\hline $2^{\mathrm{a}}$ & $\mathrm{P}-2 \mathrm{a}$ & BEOB 3 & 1 & 3 & 58 & 4.2 & 3.02 & 16 \\
\hline $3^{\mathrm{a}}$ & P-3a & BEOB 3 & 1 & 6 & 55 & 3.9 & 2.55 & 37 \\
\hline $4^{\mathrm{a}}$ & P-4a & BEOB 3 & 1 & 9 & 54 & 3.6 & 2.01 & 54 \\
\hline $5^{\mathrm{a}}$ & P-5a & BEOB 3 & 1 & 15 & 39 & 2.2 & 1.45 & 57 \\
\hline $6^{\mathrm{b}}$ & P-6a & 4,4-ВЕОВР 3 & 1 & 9 & 53 & 3.8 & 2.20 & 57 \\
\hline
\end{tabular}

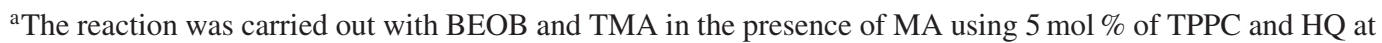
$140^{\circ} \mathrm{C}$ for $24 \mathrm{~h} .{ }^{\mathrm{b}} \mathrm{The}$ reaction was carried out with 4,4'-BEOBP and TMA in the presence of MA using $5 \mathrm{~mol} \%$ of TPPC and HQ at $140^{\circ} \mathrm{C}$ for $24 \mathrm{~h}$. ${ }^{\mathrm{c}}$ Insoluble parts in diethyl ether. ${ }^{\mathrm{d}}$ Estimated by SEC (DMF) based on polystyrene standards. ${ }^{\mathrm{e}}$ The ratio of methacryloyl groups (RM) were calculated by ${ }^{1} \mathrm{H}$ NMR as followed. [Terminal methacryloyl groups/(Terminal methacryloyl groups + Terminal oxetanyl groups + Terminal carboxyl groups) $] \times 100$. 


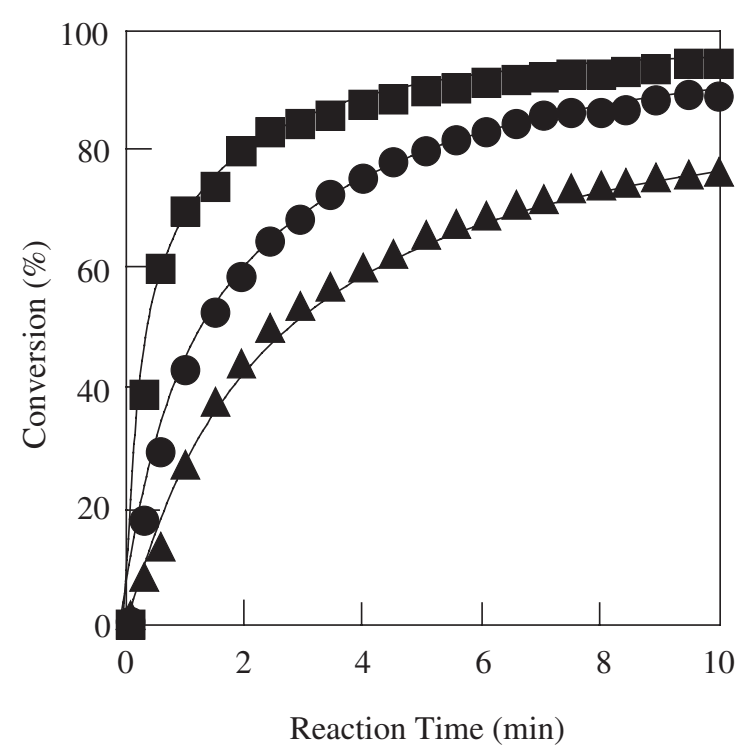

Figure 3. Time-conversion curve of the photo-initiated radical polymerization: (๑) P-4a $(97 \mathrm{wt} \%)$ and Irgacure $907^{\circledR}$ (3 wt \%); (回) P-4a (70 wt \%), Irgacure $907^{\circledR}$ (3 wt \%) and HEMA (27 wt \%); (ム) P-7a (97 wt \%) and Irgacure $907^{\circledR}$ (3 wt \%).

formed in the film state. As shown in Figure 3, the reaction rapidly proceeded, and conversions reached to 59 and $88 \%$ in 2 and 10 min, respectively. Furthermore, the photo-irradiated polymer film became insoluble in any organic solvents. On the other hand, when the photochemical reaction of P-7a $\left(M_{\mathrm{n}}=\right.$ $3800, M_{\mathrm{w}} / M_{\mathrm{n}}=2.30$ ) with linear structure was performed under the same irradiation conditions, the conversions were 43 and $76 \%$ in 2 and $10 \mathrm{~min}$, respectively. Furthermore, it was observed that the rate of photochemical reaction of P-4a was strongly enhanced by the addition of low molecular weight monomer HEMA under the same irradiation conditions, and the conversions of the mixture of P-4a (70 wt \%), HEMA (27 wt \%), and photo initiator ( $3 \mathrm{wt} \%$ ) reached to 78 and $95 \%$ at 2 and $10 \mathrm{~min}$, respectively. This means that the molecular motion and content of methacryloyl groups of the film prepared from P-4a, HEMA, and photo-initiator increased by the addition of low molecular weight monomer HEMA.

These results showed that this hyperbranched polyester with terminal methacryloyl groups had higher photochemical reactivity than the corresponding linear polyester with terminal methacryloyl groups, because the former polymer had many photo reactive groups in the end of polymer chain.

\section{Chemical Modification of the Hyperbranched Poly- ester with THPA}

Ordinarily, alkali aqueous solutions have been used as developers for negative resists. Therefore, the introduction of the carboxyl groups into P-4a was examined (Scheme 3). The reaction of P-4a $\left(M_{\mathrm{n}}=3600\right.$, $M_{\mathrm{w}} / M_{\mathrm{n}}=2.01, \mathrm{RM}=54 \%$ ) with 0.6 equiv. of THPA was carried out using TPP as a catalyst at $80^{\circ} \mathrm{C}$ for $4 \mathrm{~h}$, and it was found that the corresponding polymer P-4b containing 55\% of the pendant carboxyl groups was obtained in $79 \%$ yield. The structure of $\mathbf{P - 4 b}$ was confirmed by ${ }^{1} \mathrm{H}$ NMR and IR spectroscopy.

Solubilities of P-4a containing pendnant primary hydroxy and terminal methacryloyl groups, and $\mathbf{P}-\mathbf{4 b}$ containing pendant carboxyl and terminal methacryloyl groups were evaluated. Both polymers were well soluble in 1,4-dioxane, chloroform, ethanol, methanol, THF, acetone, DMF, NMP and DMSO, and were insoluble in diethyl ether, hexane, and toluene. P-4a was partly soluble in anisole and chlorobenzene; however, $\mathbf{P}-\mathbf{4 b}$ was insoluble in the same solvents. Furthermore, $\mathbf{P}-\mathbf{4 b}$ with pendant carboxyl groups was soluble in $1.0 \mathrm{wt} \%$ of $\mathrm{NaHCO}_{3}$ aqueous solution, $1.0 \mathrm{wt} \%$ of $\mathrm{Na}_{2} \mathrm{CO}_{3}$ aqueous solution, and $2.38 \mathrm{wt} \%$ of tetramethylammonium hydroxide (TMAH) aque-
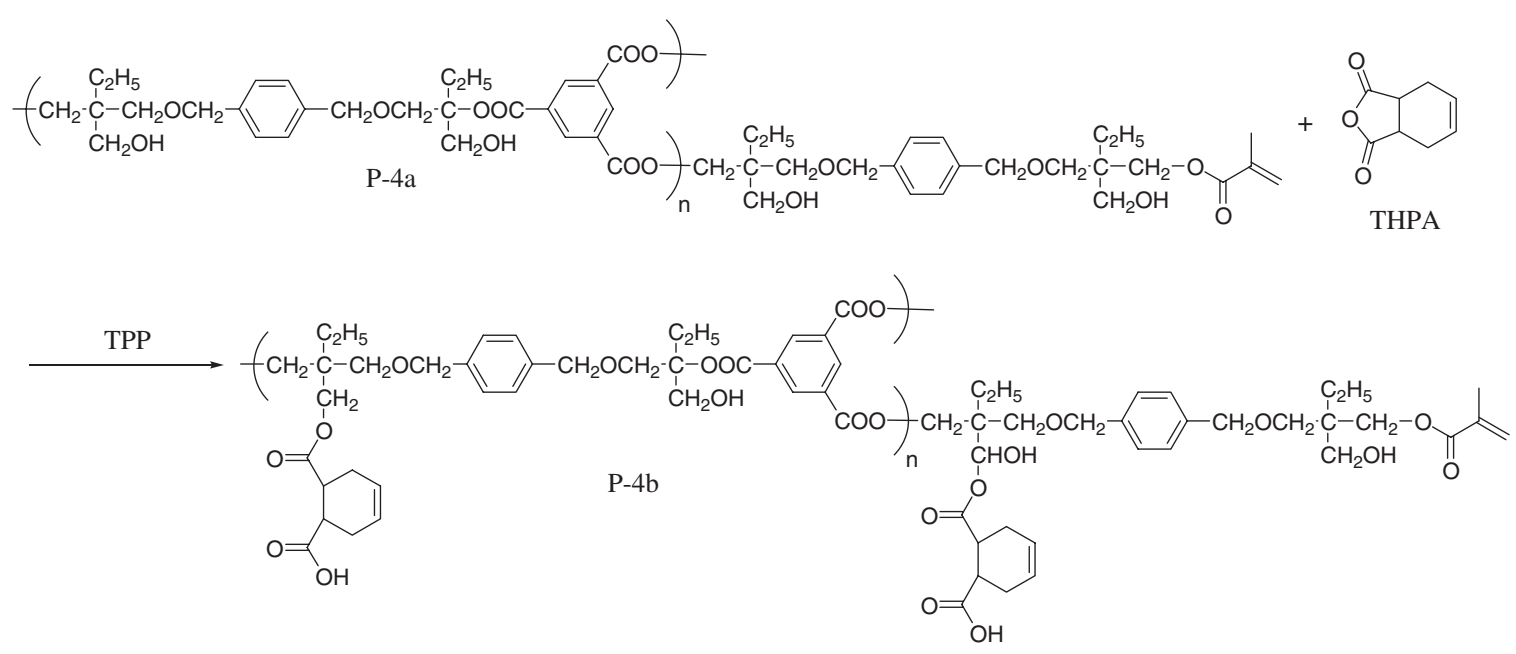

Scheme 3. 
Table II. Solubility of poly(ester)s with pendant hydroxyl or carboxyl groups ${ }^{\text {a }}$

\begin{tabular}{lcc}
\hline \multicolumn{1}{c}{ Solvent } & P-4a & P-4b \\
\hline Hexane & - & - \\
Toluene & - & - \\
Diethyl ether & - & - \\
1,4-Dioxane & ++ & ++ \\
Chloroform & ++ & ++ \\
Anisole & +- & - \\
Chlorobenzene & +- & - \\
Ethanol & ++ & ++ \\
Methanol & ++ & ++ \\
THF & ++ & ++ \\
Ethyl acetate & +- & +- \\
Acetone & ++ & ++ \\
DMF & ++ & ++ \\
NMP & ++ & ++ \\
DMSO & ++ & ++ \\
1.0 wt $\% \mathrm{NaHCO}_{3}$ & - & ++ \\
$1.0 \mathrm{wt} \% \mathrm{Na}_{2} \mathrm{CO}_{3}$ & - & ++ \\
2.38 wt $\% \mathrm{TMAH}^{\mathrm{TM}}$ & - & ++ \\
\hline
\end{tabular}

$\mathrm{a}_{++}$: soluble at room temperature, +- : partially soluble, - : insoluble.

ous solution; however, P-4a was insoluble in the same aqueous solutions (Table II). These results showed that the alkali-solubility of both polymers was dramatically changed by the introduction of certain carboxyl groups into the polymer.

\section{Thermal Properties of Hyperbranched Polymers}

Glass transition temperatures $\left(T_{\mathrm{g}} \mathrm{s}\right)$ and $5 \mathrm{wt} \%$ weight loss temperatures $\left(T_{\mathrm{d}}{ }^{5 \%} \mathrm{~s}\right)$ of the synthesized polymer $\mathbf{P}-\mathbf{4 a}$, which had pendant primary hydroxy groups and terminal methacryloyl groups, and $\mathbf{P}-\mathbf{4 b}$ with pendant carboxyl groups and terminal methacryloyl groups were measured by DSC and TGA, respectively. As summarized in Table III, P-4a with hy-
Table III. Thermal properties of P-4a and P-4b

\begin{tabular}{cccc}
\hline Run & Polymer & $T_{\mathrm{g}}\left({ }^{\circ} \mathrm{C}\right)^{\mathrm{a}}$ & $T_{\mathrm{d}}^{5 \%}\left({ }^{\circ} \mathrm{C}\right)^{\mathrm{b}}$ \\
\hline 1 & P-4a & 18 & 268 \\
2 & P-4b & 21 & 258 \\
\hline
\end{tabular}

${ }^{\mathrm{a}}$ Measured by DSC at a heating rate of $10^{\circ} \mathrm{C} / \mathrm{min}$ under nitrogen. ${ }^{\mathrm{b}}$ Measured by TG/DTA at a heating rate of $10^{\circ} \mathrm{C} /$ min under nitrogen.

droxy groups showed $T_{\mathrm{g}}$ at $18^{\circ} \mathrm{C}$. On the other hand, the $T_{\mathrm{g}}$ of $\mathbf{P}-\mathbf{4} \mathbf{b}$ with carboxyl groups was $21^{\circ} \mathrm{C}$. This result shows that $T_{\mathrm{g}}$ of the hyperbranched polymer with pendant hydroxy groups increased by the introduction of pendant carboxyl groups, although the expected dramatical rise was not found.

Furthermore, we examined $5 \mathrm{wt} \%$ loss temperatures $\left(T_{\mathrm{d}}{ }^{5 \%}\right)$ of P-4a and P-4b. As summarized in Table III, $T_{\mathrm{d}}{ }^{5 \%}$ of $\mathbf{P}-\mathbf{4 a}$ and $\mathbf{P}-\mathbf{4 b}$ were 268 and $258^{\circ} \mathrm{C}$, respectively. This result suggests that the weight-loss temperatures of the hyperbranched polymer P-4a with pendant hydroxy groups was fallen by the introduction of the pendant carboxyl groups. That is, lower $T_{\mathrm{d}}{ }^{5 \%}$ of $\mathbf{P}-\mathbf{4 b}$ was caused by the elimination of low molecular weight THPA from the polymer.

We also compared the $T_{\mathrm{d}}^{5 \%}$ of $\mathbf{P}-\mathbf{4 b}$ with that of the other type of hyperbranched polyester ${ }^{19}$ (ref 1) with pendant carboxyl groups and terminal methacryloyl groups, which was prepared by the polyaddition of di(glycidyl ether) of bisphenol-A with TMA and MA followed by the reaction with THPA under similar reaction conditions, from the view point of the practical application as solder resist. As shown in Figure 4, although the $T_{\mathrm{d}}{ }^{5 \%}$ of $\mathbf{P}-\mathbf{4} \mathbf{b}$ was $258^{\circ} \mathrm{C}$, the $T_{\mathrm{d}}{ }^{5 \%}$ of ref 1 was $225^{\circ} \mathrm{C}$. This means that $\mathbf{P}-\mathbf{4 b}$ prepared from the reaction of bis(oxetane) had better thermal stability than ref 1 prepared from the reaction of bis(epoxide) in the initial stage. These differences might come

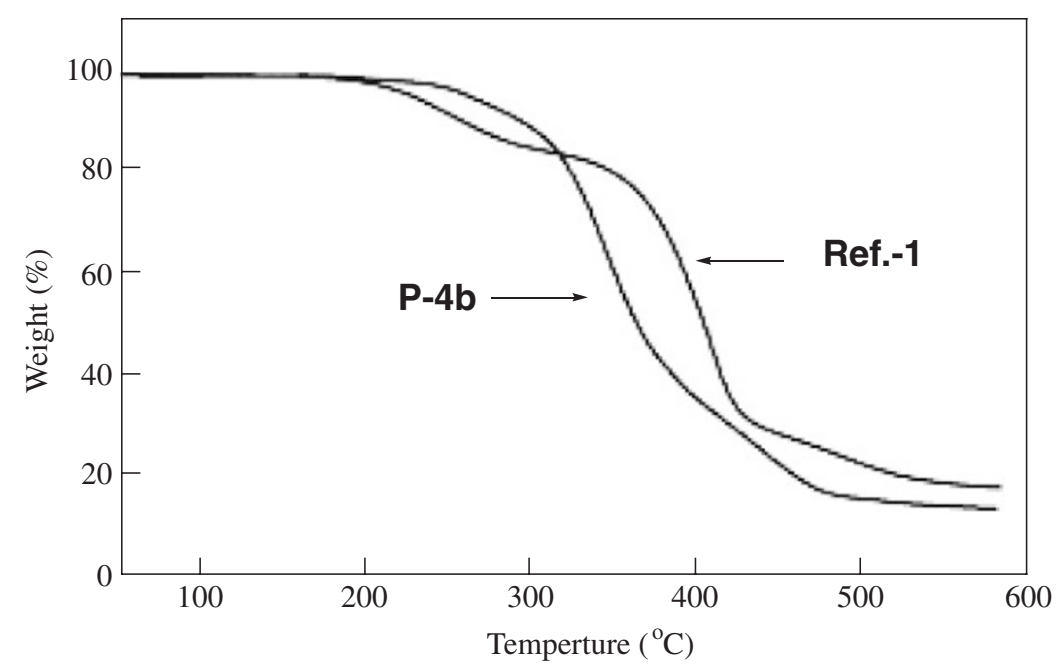

Figure 4. TGA profiles of polymer. 
Table IV. Composition of solder resists ${ }^{\mathrm{a}}$

\begin{tabular}{lrlll}
\hline Composition & & \multicolumn{1}{c}{ Sample 1 } & \multicolumn{1}{c}{ Sample 2 } & \multicolumn{1}{c}{ ref 2 } \\
\hline Main resin & $58 \mathrm{wt} \%$ & P-4b & P-6b & SP-3500 \\
Diluents & $12 \mathrm{wt} \%$ & DPEHA & DPEHA & DPEHA \\
Photo-initiator & $5 \mathrm{wt} \%$ & Irgacure 907 & Irgacure 907 & Irgacure 907 \\
Curing agent & $24 \mathrm{wt} \%$ & Epoxy resin & Epoxy resin & Epoxy resin \\
Additive & $1 \mathrm{wt} \%$ & Dicyandiamine & Dicyandiamine & Dicyandiamine \\
\hline
\end{tabular}

${ }^{a}$ Diethylene glycol monoethyl ether acetate ( $40 \mathrm{wt} \%$ to P-4b) was used as a solvent.

from the ester linkage of pendant carboxyl moieties. That is, the pendant ester linkage composed from $s e c$-alcohol unit in ref $\mathbf{1}$ decomposed easily at lower temperature to remove THPA molecule than the ester linkage composed from primary-alcohol unit in $\mathbf{P}-\mathbf{4} \mathbf{b}$.

\section{Evaluation of Solder Resist Based on Polyester P-4b} with both Photoreactive Methacryloyl Groups and Alkaline Developable Carboxyl Groups

The patterning property of the prepared solder resist was measured with a SEM image.

The resist solution composed from the mixture of main resin (P-4b with 55\% of the pendant carboxyl groups), diluents, photo-initiator, thermal-curing agent, and additive are summarized in Table IV. The resist solution coated on the substrate was dried to form the resist film ( $50 \mu \mathrm{m}$ thick) and exposed by the UV light. After that, the exposed resist film on the substrates was developed with $1 \mathrm{wt} \%$ of $\mathrm{Na}_{2} \mathrm{CO}_{3}$ aqueous solution. Figure 5 showed a SEM image of the contact-printed negative pattern, which was postbaked at $150^{\circ} \mathrm{C}$ for $60 \mathrm{~min}$ after lithography process. This result showed that the solder resist composed mainly from $\mathbf{P}-\mathbf{4 b}$ was capable of very high resolving such as $55 \mu \mathrm{m}$ line width.

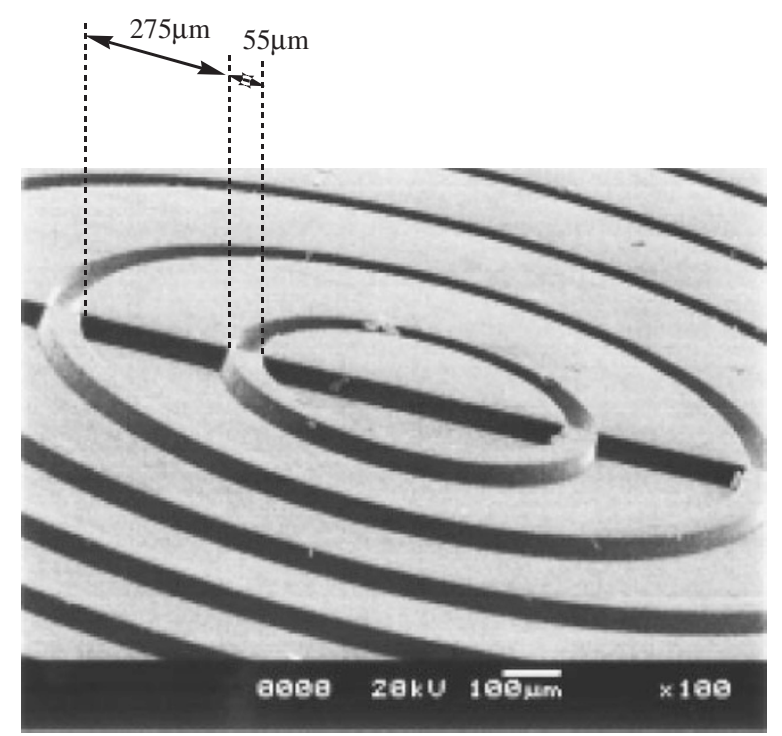

Figure 5. SEM image of the pattern.

\section{CONCLUSIONS}

We have investigated synthesis and photo-initiated radical polymerization of hyperbranched poly(ester)s with both photosensitive groups and alkali-developable groups. Novel hyperbranched poly(ester)s with methacryloyl groups were synthesized by the polyaddition of bis(oxetane)s with TMA and MA. The chemical modification of the synthesized hyperbranched poly(ester)s was carried out with THPA to afford the alkali developable polymer containing pendant carboxyl groups. It was also found that the polymer $(\mathbf{P}-\mathbf{4 b})$ prepared from the reaction of BEOB with TMA and MA followed by the reaction with THPA had higher $T_{\mathrm{d}}{ }^{5 \%}$ than other type of hyperbranched polyester (ref 1) prepared from the reaction of bis(epoxide) with TMA and MA followed by the reaction with THPA. Negative-type solder resist based on $\mathbf{P}-\mathbf{4} \mathbf{b}$, photo-initiator, diluents, curing agent, and additive was prepared, and lithographic behavior was evaluated. As a result, it was found that this solder resist has excellent resolution such as $55 \mu \mathrm{m}$ line width when $50 \mu \mathrm{m}$ thick film is used.

\section{REFERENCES}

1. For example: T. Nishikubo Ed., Synthesis and Application of Photosensitive Polymers, CMC, Tokyo, 1979.

2. For example: Y. Tabata, Y. Takimoto, Y. Tominaga, H. Nakamoto, and T. Nishikubo Eds. Ultraviolet and Electron Beam Curable Materials, CMC, Tokyo, 1989.

3. For example: Y. Tabata, T. Isobe, T. Otaka, M. Sato, M. Takayama, Y. Tominaga, and T. Nishikubo, Eds., Technology \& Application of UV/EB Curing, CMC, Tokyo, 1997.

4. T. Nishikubo, M. Imaura, T. Mizuko, and T. Takaoka, J. Appl. Polym. Sci., 18, 3445 (1974).

5. T. Nishikubo, Kobunshi Ronbunshu, 35, 673 (1978).

6. NOK Co. Ltd. (Investigaters, T. Nishikubo, S. Ugai, T. Ichijo, and M. Kishida), Japan Patent 11470627, (May. 26, 1983).

7. P. J. Flory, J. Am. Chem. Soc., 74, 2718 (1952).

8. Y. H. Kim, J. Polym. Sci., Part A: Polym. Chem., 36, 1685 (1998).

9. M. Jikei and M. Kakimoto, Prog. Polym. Sci., 26, 1233 (2001).

10. M. Jikei, S. Chon, M. Kakimoto, S. Kawauchi, T. Imase, and 
J. Watanabe, Macromolecules, 32, 2061 (1999).

11. S. Makita, H. Kudo, and T. Nishikubo, J. Polym. Sci., Part A: Polym. Chem., 42, 3697 (2004).

12. H. Chen and J. Yin, J. Polym. Sci., Part A: Polym. Chem., 42, 1735 (2004).

13. L. Tang, Y. Fang, and J. Feng, Polym. J., 37, 255 (2005).

14. T. Nishikubo, A. Kameyama, and A. Suzuki, React. Funct. Polym., 37, 19 (1998).

15. T. Nishikubo, A. Kameyama, M. Ito, T. Nakajima, and H. Miyazaki, J. Polym. Sci., Part A: Polym. Chem., 37, 2781
(1999).

16. Y. Konno, H. Suzuki, H. Kudo, A. Kameyama, and T. Nishikubo, Polym. J. 36, 114 (2004).

17. T. Nishikubo, H. Kudo, M. Yoshihara, and K. Maruyama, J. Polym. Sci., Part A: Polym. Chem., 43, 2028 (2005).

18. T. Nishikubo, H. Kudo, and T. Nakagami, Polym. J. in press.

19. K. Maruyama, H. Kudo, T. Ikehara, N. Ito, and T. Nishikubo, J. Polym. Sci., Part A: Polym. Chem., 43, 4642 (2005). 